\title{
Laparoscopic appendectomy versus open appendectomy for suspected appendicitis during pregnancy: a systematic review and updated meta-analysis
}

\author{
Seung Hwan Lee ${ }^{1}$, Jin Young Lee ${ }^{2}$ Yoon Young Choi ${ }^{1}$ and Jae Gil Lee ${ }^{1 *}$ (D)
}

\begin{abstract}
Background: Recently, laparoscopic appendectomies (LAs) have been widely performed instead of open appendectomies (OAs) during pregnancy. However, concerns about the safety of LA during pregnancy remain. This systematic review and meta-analysis aimed to evaluate the current evidence relating to the safety of LA versus OA for suspected appendicitis during pregnancy.

Methods: Comprehensive literature searches were conducted using the PubMed, EMBASE, and Cochrane Library databases to identify articles describing LA versus OA in pregnancy, without restrictions regarding the publication date. The primary endpoints were fetal loss and preterm delivery.

Results: After screening 801 studies, 22 comparative cohort studies were included in the analysis, which involved 4694 women, of whom 905 underwent LAs and 3789 underwent OAs. Fetal loss was significantly higher among those who underwent LAs compared with those who underwent OAs, and the pooled odds ratio (OR) was 1.72 (95\% confidence interval [CI]: 1.22-2.42) without heterogeneity. The sensitivity analysis showed that the effect size was influenced by one of the studies, because its removal resulted in there being no significant difference between $\mathrm{LA}$ and $\mathrm{OA}$ with respect to the risk of fetal loss (OR 1.163,95\% Cl: $0.68-1.99 ; P=0.581)$. A significant difference was not evident between $L A$ and $O A$ with respect to preterm delivery (OR $0.76,95 \% \mathrm{Cl}: 0.51-1.15)$, a result that did not change following the sensitivity analysis. The patients who underwent LA had shorter hospital stays (mean difference - 1.01, 95\% Cl: -1.61--0.41) and a lower wound infection risk (OR 0.40, 95\% Cl: 0.21-0.76) compared with those who underwent OA.

Conclusion: It is not reasonable to conclude that LA in pregnant women might be associated with a greater risk of fetal loss. The difference between LA and OA with respect to preterm delivery was not significant.
\end{abstract}

Keywords: Pregnancy, Appendicitis, Laparoscopy, Appendectomy

\section{Background}

Acute appendicitis is the most common nonobstetric surgical problem that occurs during pregnancy, and its incidence varies widely, with rates ranging from 1.8 to 41 per 10,000 pregnancies [1-6]. The incidence of appendicitis has been reported to be higher during the second trimester than during the first or third trimesters of

\footnotetext{
* Correspondence: jakii@yuhs.ac

'Department of Surgery, Yonsei University College of Medicine, 50-1

Yonsei-ro, Seodaemun-gu, Seoul 03722, Republic of Korea

Full list of author information is available at the end of the article
}

pregnancy [2, 4, 7-10]. Diagnosing acute appendicitis during pregnancy is challenging for surgeons, because of difficulties associated with nonspecific abdominal symptoms, and the physiologic leukocytosis and the anatomic changes in the appendix that occur during pregnancy.

Appendicitis during pregnancy has been reported to be associated with poor pregnancy outcomes, including fetal loss, preterm delivery, and perinatal morbidity and mortality [11]. Fetal loss occurs in $20 \%$ of women with complicated appendicitis compared with $1.5 \%$ of women with uncomplicated appendicitis [12-15]. The preterm

(C) The Author(s). 2019 Open Access This article is distributed under the terms of the Creative Commons Attribution 4.0 International License (http://creativecommons.org/licenses/by/4.0/), which permits unrestricted use, distribution, and 
delivery rate has been reported to be between 7.5 and $30.0 \%$, and preterm delivery occurs more frequently in women with perforated appendicitis [16-26].

Open appendectomy (OA) has been performed on patients with acute appendicitis of both sexes and of all ages, including pregnant women. Moreover, laparoscopic appendectomy (LA) has also become a standard procedure for acute appendicitis since it was first performed in 1983 [27]. Although pregnancy was considered an absolute or relative contraindication for laparoscopic procedures initially, LA has recently been routinely performed in pregnant women in accordance with the recommendations in the guidelines published by the Society of American Gastrointestinal and Endoscopic Surgeons (SAGES) [28]. However, a systematic review [5] and a meta-analysis [4] concluded that there was low grade evidence to suggest that LA in pregnant women might be associated with a greater risk of fetal loss. Therefore, the optimal surgical approach for acute appendicitis during pregnancy remains a matter of debate. Thus, the aim of this systematic review and updated meta-analysis was to evaluate the current evidence regarding the safety of LA versus OA for suspected appendicitis during pregnancy.

\section{Methods}

This systematic review was conducted and is reported according to the Preferred Reporting Items for Systematic Reviews and Meta-Analyses guidelines [29].

\section{Search strategy and study selection}

Three major electronic medical databases, namely, PubMed, the Cochrane Central Register of Controlled Trials, and EMBASE, were comprehensively searched to find suitable studies using the following search terms: "pregnancy", "pregnant women", "appendicitis", "appendectomy", and "laparoscopy". We restricted the searches to studies that were conducted on human subjects and those that were published in English, but there was no restriction regarding the publication date.

The present review included any comparative studies that compared the outcomes from LA and OA for appendicitis in pregnant patients. Those studies with at least one pregnancy outcome, for example, fetal loss, preterm delivery, birth weight, or the Apgar score, or one surgical outcome, for example, the wound infection rate, the intra-abdominal abscess rate, the operative time, or the length of stay (LOS), were included. Case series, review articles, and articles written in languages other than English were excluded from this review. When there were duplicate publications, the study with the largest number of subjects was selected.

The titles and the abstracts of the extracted studies were reviewed independently by two researchers (SHL and JYL). The complete manuscripts were reviewed if the abstracts did not provide enough information to indicate suitability for the study. The studies were finally included in the systematic review and meta-analysis after full-text evaluations were performed independently. Any discrepancies were resolved through discussion.

\section{Study outcomes and data extraction}

This study's primary endpoints were the pregnancy outcomes, including fetal loss and preterm delivery. The data extracted that included the publications' general data (author, year of publication, and journal), the studies' characteristics (the study's design, the study period, and the sample size), the baseline characteristics of the studies' populations (age, gestational age at surgery, and delivery type), the pregnancy outcomes (fetal loss, preterm delivery, birth weight, and the Apgar score), and the surgical outcomes (wound infection and intra-abdominal abscess rates, operative time, LOS, and the presence of complicated appendicitis), were summarized and analyzed. All of the data were cross-checked independently by two authors (SHL and JYL).

\section{Statistical analysis}

The statistical analyses were performed using Review Manager, version 5.3 (RevMan; Nordic Cochrane Centre, Cochrane Collaboration, Copenhagen, Denmark) and Comprehensive Meta-Analysis, version 2 (Biostat, Englewood, NJ, USA). For the continuous outcomes, the results were pooled using the inverse-variance method and the mean differences (MDs) and their 95\% confidence intervals (CIs) were calculated. For the dichotomous outcomes, the pooled odds ratios (ORs) and their 95\% CIs were calculated using the Mantel-Haenszel method. The heterogeneity of the effect size across the studies was tested using Cochran's Q test, with the significance level set at $P<0.10$, and an $\mathrm{I}^{2}$ statistic with a value of $\geq 50 \%$ was considered to indicate substantial heterogeneity. A fixed effects model was used to pool the results when heterogeneity was not suspected, otherwise, a random-effects model was used. Publication bias was evaluated by assessing funnel plot symmetry. A sensitivity analysis, which involved repeating the sequential pooling outcomes while excluding each study in turn, was performed to evaluate whether the overall results were robust in relation to the excluded studies. Meta-regression analyses were performed to examine whether the primary outcomes were associated with other characteristics of the studies, for example, the publication year, complicated appendicitis, the gestational age, the pregnancy trimester, or a negative appendectomy. 


\section{Results}

\section{Search results}

The study selection flow diagram is shown in Fig. 1. In total, 801 studies were identified. After screening the titles and the abstracts, 46 articles underwent full-text assessments, which led to the exclusion of 24 studies; therefore 22 comparative studies involving a total of 4694 women, of whom 905 underwent LAs and 3789 underwent OAs, were eligible for inclusion.

\section{Study characteristics}

The characteristics of the included studies are presented in Table 1 [3, 16-26, 30-39]. Three studies [33, 36, 38] were comparative prospective cohort studies and nineteen studies [3, 16-26, 30-32, 34, 35, 37, 39] were comparative retrospective reviews of patients' medical records. The studies were conducted between 1996 and 2016 in the United States of America $(n=9)$ [25, 26, $30,33-35,37-39]$, Korea $(n=4)$ [16, 20, 22, 23], Israel $(n=3)[3,19,36]$, Turkey $(n=2)[17,31]$, China $(n=1)$ [18], India $(n=1)$ [21], Netherlands $(n=1)$ [24], and Tunisia $(n=1)$ [32]. The patients' mean ages ranged from 22.8 years to 30.8 years. Surgery occurred mostly during the second trimester, except in the studies by
Eom et al. [23] and Upadhyay et al. [33]. The negative appendectomy rate ranged from 0 to $42.9 \%$. The complicated appendicitis rate ranged from 0 to $31.3 \%$. Fetal losses were reported in 21 studies [3, 16-26, 31-39], and preterm deliveries were reported in 16 studies [16-26, 33, 35-38]. In addition, the birth weights were reported in eight studies [3, 16, 17, 19, 20, 23, 25, 35], and the Apgar scores were reported in six studies $[3,17,19,20,25,35]$.

\section{Pregnancy outcomes}

The risk of fetal loss was significantly higher in the women who underwent LA compared with those who underwent OA, and the pooled OR was 1.72 (95\% CI: 1.22-2.42) in the fixed effects model $\left(P=0.89 ; \mathrm{I}^{2}=0 \%\right)$ (Fig. 2). The one-study removed analysis showed that the study by McGory et al. [34] had a relatively strong influence on the results, and removing this study from the analysis showed that there was no significant difference between LA and OA with respect to the risk of fetal loss (OR 1.163, 95\% CI: 0.68-1.99; $P=0.581$ ) (Fig. 3).

No significant difference was evident between LA and OA with respect to preterm delivery (OR 0.76, 95\% CI: $0.51-1.15)$ in the fixed effects model $\left(P=0.92 ; \mathrm{I}^{2}=0 \%\right)$ (Fig. 4). Moreover, the sensitivity analysis did not show

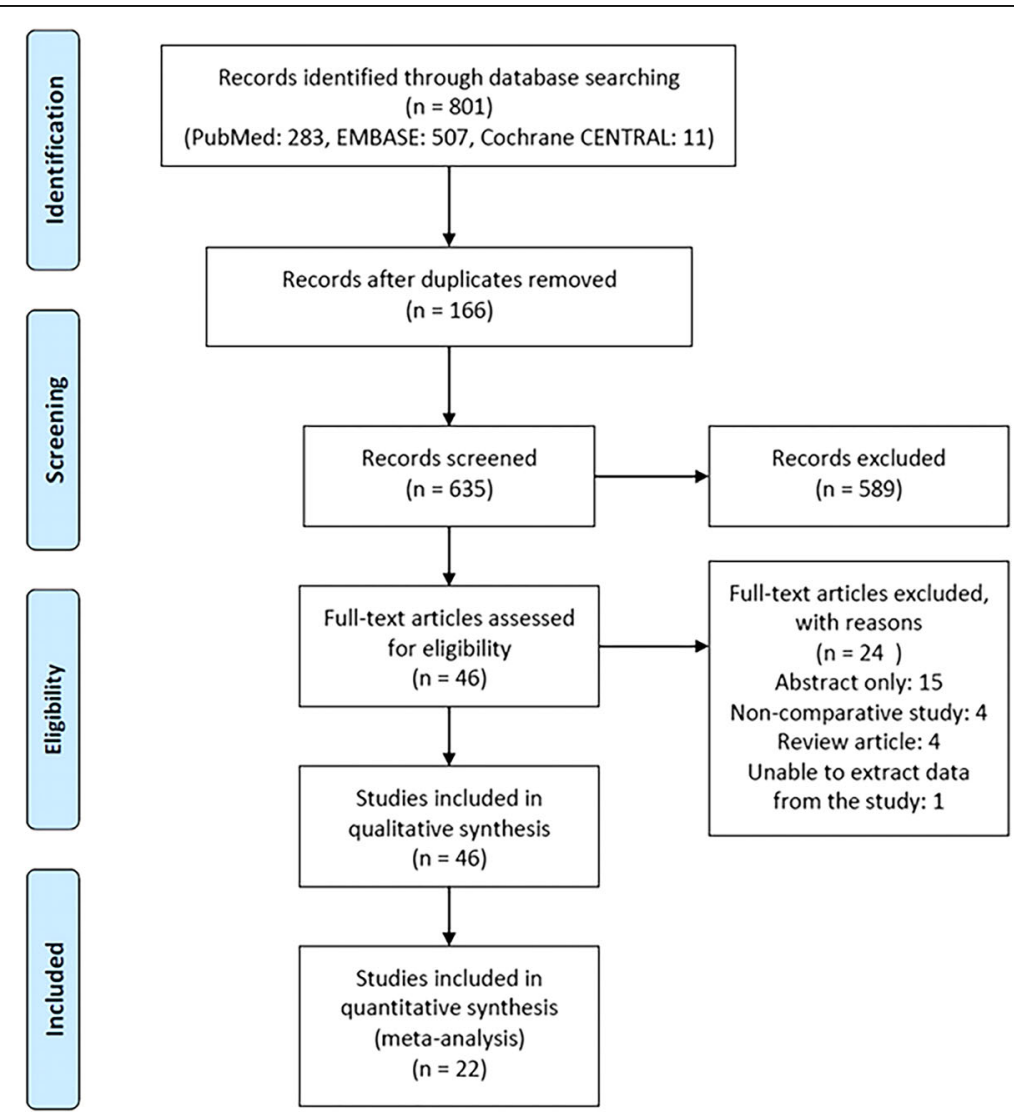

Fig. 1 Flow diagram of the literature search and study selection 
Table 1 Baseline characteristics of the included studies

\begin{tabular}{|c|c|c|c|c|c|c|c|c|c|c|}
\hline \multirow[t]{2}{*}{ Reference } & \multirow[t]{2}{*}{ Year } & \multirow[t]{2}{*}{ Study design } & \multirow{2}{*}{$\begin{array}{l}\text { Age } \\
\text { (years) }^{\text {a }}\end{array}$} & \multirow{2}{*}{$\begin{array}{l}\text { GA } \\
(\text { weeks })^{a}\end{array}$} & \multicolumn{3}{|c|}{ No. of Women } & \multirow{2}{*}{$\begin{array}{l}\text { Negative } \\
\text { appendectomy } \\
(\%)\end{array}$} & \multirow{2}{*}{$\begin{array}{l}\text { Complicated } \\
\text { appendicitis } \\
(\%)\end{array}$} & \multirow[t]{2}{*}{ Outcomes } \\
\hline & & & & & Total & LA & $\mathrm{OA}$ & & & \\
\hline Yoo et al. [16] & 2016 & Retrospective & 30.8 & 20.2 & 80 & 24 & 56 & NA & 31.3 & $\begin{array}{l}\text { Fetal loss, preterm delivery, } \\
\text { LOS, operative time, birth } \\
\text { weight, wound infection, } \\
\text { intraabdominal abscess }\end{array}$ \\
\hline Karaman et al. [17] & 2016 & Retrospective & 22.8 & 24.9 & 48 & 12 & 36 & NA & NA & $\begin{array}{l}\text { Fetal loss, preterm delivery, } \\
\text { LOS, operative time, Apgar } \\
\text { score, birth weight, wound } \\
\text { infection, intraabdominal } \\
\text { abscess }\end{array}$ \\
\hline Cox et al. [30] & 2016 & Retrospective & 27.9 & NA & 1335 & 894 & 441 & NA & 9.0 & $\begin{array}{l}\text { Operative time, wound } \\
\text { infection, LOS, intraabdominal } \\
\text { abscess }\end{array}$ \\
\hline Cheng et al. [18] & 2015 & Retrospective & NA & NA & 781 & 128 & 653 & NA & 15.5 & Fetal loss, preterm delivery, LOS \\
\hline Peled et al. [19] & 2014 & Retrospective & 28.1 & 17.9 & 85 & 26 & 59 & 17.6 & 12.9 & $\begin{array}{l}\text { Fetal loss, preterm delivery, LOS, } \\
\text { Apgar score, birth weight, }\end{array}$ \\
\hline Kapan et al. [31] & 2013 & Retrospective & 26.2 & 17.5 & 17 & 7 & 10 & NA & NA & Fetal loss, LOS, operative time, \\
\hline Chung et al. [20] & 2013 & Retrospective & 30.6 & 16.6 & 61 & 22 & 39 & 9.8 & 11.5 & $\begin{array}{l}\text { Fetal loss, preterm delivery, LOS, } \\
\text { operative time, Apgar score, birth } \\
\text { weight, wound infection, } \\
\text { intraabdominal abscess }\end{array}$ \\
\hline Miloudi et al. [32] & 2012 & Retrospective & NA & NA & 27 & 16 & 11 & NA & 14.8 & Fetal loss \\
\hline Khan et al. [21] & 2012 & Retrospective & 22.8 & 17.3 & 118 & 52 & 66 & NA & NA & $\begin{array}{l}\text { Fetal loss, preterm delivery, LOS, } \\
\text { operative time, wound infection, } \\
\text { intraabdominal abscess }\end{array}$ \\
\hline Jung et al. [22] & 2012 & Retrospective & 27.9 & 15.4 & 25 & 4 & 21 & 0 & NA & $\begin{array}{l}\text { Fetal loss, preterm delivery, LOS, } \\
\text { wound infection }\end{array}$ \\
\hline Eom et al. [23] & 2012 & Retrospective & 29.1 & 38.7 & 43 & 15 & 28 & 0 & 23.3 & $\begin{array}{l}\text { Fetal loss, preterm delivery, LOS, } \\
\text { operative time, birth weight, } \\
\text { intraabdominal abscess }\end{array}$ \\
\hline De Bakker et al. [24] & 2011 & Retrospective & NA & NA & 15 & 12 & 3 & 3.0 & NA & $\begin{array}{l}\text { Fetal loss, preterm delivery, LOS, } \\
\text { operative time }\end{array}$ \\
\hline Sadot et al. [25] & 2010 & Retrospective & 29.5 & 19.7 & 65 & $48^{\mathrm{b}}$ & $17^{b}$ & 24.1 & 12.3 & $\begin{array}{l}\text { Fetal loss, preterm delivery, LOS, } \\
\text { operative time, Apgar score, birth } \\
\text { weight, wound infection }\end{array}$ \\
\hline Corneille et al. [26] & 2010 & Retrospective & $25.6(6.4)$ & $15.9(8.4)$ & 49 & 9 & 40 & NA & NA & Fetal loss, preterm delivery, LOS \\
\hline Kirshtein et al. [3] & 2009 & Retrospective & 28.4 & $13.9(6.0)$ & 42 & 23 & 19 & 42.9 & 19.0 & $\begin{array}{l}\text { Fetal loss, LOS, operative time, } \\
\text { Apgar score, birth weight, } \\
\text { wound infection }\end{array}$ \\
\hline Upadhyay et al. [33] & 2007 & Prospective & $27.2(3.3)$ & $32(2.6)$ & 6 & 4 & 2 & NA & NA & Fetal loss, preterm delivery \\
\hline McGory et al. & 2007 & Retrospective & $27.2(6.0)$ & NA & 3133 & 454 & 2679 & 23.1 & 25.3 & Fetal loss \\
\hline Carver et al. [34] & 2005 & Retrospective & $23.4(5.8)$ & $14(5.4)$ & 28 & 17 & 11 & NA & NA & $\begin{array}{l}\text { Fetal loss, preterm delivery, LOS, } \\
\text { Apgar score, birth weight, } \\
\text { wound infection }\end{array}$ \\
\hline Lyass et al. [36] & 2001 & Prospective & $28.5(15.2)$ & $20(6.3)$ & 22 & 11 & 11 & 31.8 & 0 & $\begin{array}{l}\text { Fetal loss, preterm delivery, LOS, } \\
\text { operative time }\end{array}$ \\
\hline Affleck et al. [37] & 1999 & Retrospective & NA & NA & 37 & 19 & 18 & NA & NA & Fetal loss, preterm delivery \\
\hline Gurbuz et al. [38] & 1997 & Prospective & $24.5(1.5)$ & $20.1(9.0)$ & 9 & 5 & 4 & NA & NA & $\begin{array}{l}\text { Fetal loss, preterm delivery, LOS, } \\
\text { operative time }\end{array}$ \\
\hline Curet et al. [39] & 1996 & Retrospective & NA & NA & 11 & 4 & 7 & NA & NA & Fetal loss \\
\hline
\end{tabular}

aalues are the means (standard deviations)

${ }^{\mathrm{b}}$ Missing data, 41 vs 16

NA not available, GA gestational age, LA laparoscopic appendectomy, OA open appendectomy, LOS length of stay 


\begin{tabular}{|c|c|c|c|c|c|c|c|c|c|c|}
\hline Study or Subgroup & $\begin{array}{r}\text { LA } \\
\text { Events } \\
\end{array}$ & Total & $\begin{array}{r}\text { OA } \\
\text { Events }\end{array}$ & Total & Weight & $\begin{array}{c}\text { Odds Ratio } \\
\text { M-H, Fixed, } 95 \% \mathrm{Cl}\end{array}$ & & $\begin{array}{r}\text { Odds } \\
\text { M-H, Fixe }\end{array}$ & $\begin{array}{l}\text { Ratio } \\
\text { d. } 95 \% \mathrm{Cl}\end{array}$ & \\
\hline Yoo et al. & 3 & 24 & 4 & 56 & $4.7 \%$ & $1.86[0.38,9.02]$ & & & & \\
\hline Karaman et al. & 1 & 12 & 1 & 36 & $1.0 \%$ & $3.18[0.18,55.19]$ & & & & \\
\hline Cheng et al. & 7 & 128 & 37 & 653 & $25.9 \%$ & $0.96[0.42,2.21]$ & & - & & \\
\hline Peled et al. & 1 & 26 & 0 & 59 & $0.7 \%$ & $7.00[0.28,177.68]$ & & & & \\
\hline Kapan et al. & 0 & 7 & 0 & 10 & & Not estimable & & & & \\
\hline Chung et al. & 0 & 22 & 0 & 39 & & Not estimable & & & & \\
\hline Miloudi et al. & 1 & 16 & 1 & 11 & $2.5 \%$ & $0.67[0.04,11.94]$ & & & & \\
\hline Khan et al. & 0 & 52 & 0 & 66 & & Not estimable & & & & \\
\hline Jung et al. & 0 & 4 & 2 & 21 & $1.9 \%$ & $0.87[0.04,21.36]$ & & & & \\
\hline Eom et al. & 0 & 15 & 0 & 28 & & Not estimable & & & & \\
\hline De Bakker et al. & 1 & 12 & 0 & 3 & $1.5 \%$ & $0.91[0.03,27.83]$ & & & & \\
\hline Sadot et al. & 1 & 41 & 0 & 16 & $1.6 \%$ & $1.22[0.05,31.57]$ & & & & \\
\hline Corneille et al. & 0 & 9 & 3 & 40 & $2.9 \%$ & $0.56[0.03,11.88]$ & & & & \\
\hline Kirshtein et al. & 1 & 23 & 1 & 19 & $2.4 \%$ & $0.82[0.05,14.02]$ & & & & \\
\hline Upadhyay et al. & 0 & 4 & 0 & 2 & & Not estimable & & & & \\
\hline McGory et al. & 31 & 454 & 88 & 2679 & $53.7 \%$ & $2.16[1.41,3.29]$ & & & -1 & \\
\hline Carver et al. & 2 & 17 & 0 & 11 & $1.2 \%$ & $3.71[0.16,84.92]$ & & & & \\
\hline Lyass et al. & 0 & 11 & 0 & 11 & & Not estimable & & & & \\
\hline Affleck et al. & 0 & 19 & 0 & 18 & & Not estimable & & & & \\
\hline Gurbuz et al. & 0 & 5 & 0 & 4 & & Not estimable & & & & \\
\hline Curet et al. & 0 & 4 & 0 & 7 & & Not estimable & & & & \\
\hline Total $(95 \% \mathrm{Cl})$ & & 905 & & 3789 & $100.0 \%$ & $1.72[1.22,2.42]$ & & & & \\
\hline Total events & 49 & & 137 & & & & & & & \\
\hline \multicolumn{7}{|c|}{$\begin{array}{l}\text { Heterogeneity: } \mathrm{Chi}^{2}=5.66, d f=11(P=0.89) ; I^{2}=0 \% \\
\text { Test for overall effect: } Z=3.11(P=0.002)\end{array}$} & 0.005 & $\begin{array}{c}0.1 \\
\text { Favours [LA] }\end{array}$ & $\begin{array}{c}10 \\
\text { Favours [OA] }\end{array}$ & 200 \\
\hline
\end{tabular}

Fig. 2 Forest plot comparing fetal loss after laparoscopic appendectomy versus open appendectomy. LA: laparoscopic appendectomy; OA: open appendectomy; Cl: confidence interval

any changes in relation to preterm delivery after the exclusion of specific studies (Fig. 5).

The meta-analyses of the other pregnancy outcomes, for example, birth weight and the Apgar score, are shown in Table 2 . The birth weight $(n=409)$ did not show a significant MD between LA and OA (MD 0.01, 95\% CI: $-0.09-0.10 ; P=0.88)$ in the fixed effects model $\left(P=1.00 ; \mathrm{I}^{2}=0 \%\right)$. The LA and the OA groups were compared in relation to the Apgar scores in five studies (Apgar score at $1 \mathrm{~min}$ : $n=287$; Apgar score at 5 min: $n=219$ ). The data were heterogeneous (Apgar score at $1 \mathrm{~min}: P=0.03 ; \mathrm{I}^{2}=66 \%$; Apgar score at 5 $\min : P<0.001 ; \mathrm{I}^{2}=84 \%$ ), and the unstandardized MDs were 0.12 (95\% CI: $-0.18-0.08 ; P=0.43$ ) for the Apgar score at $1 \mathrm{~min}$ and -0.02 (95\% CI: $-0.16-0.12 ; P=0.76$ ) for the Apgar score at $5 \mathrm{~min}$, indicating that there were no significant differences between the groups with respect to the Apgar scores.

\section{Surgical outcomes}

Data describing the wound infection and intra-abdominal abscess rates, the operative times, and the LOS were pooled across the studies (Table 2). Nine of the studies reported the wound infection rates $[3,16,17,20-22,25$, $30,35]$, and the pooled results showed that there was a significantly lower risk of wound infection in the LA group compared with that in the OA group (OR 0.40, 95\% CI: $0.21-0.76 ; P=0.005)$. Seventeen of the studies reported the LOS $[3,16-26,30,31,35,36,38]$, and, of these, 12 reported the means and standard deviations [3, $16,17,19-22,25,26,30,31,35]$. The five remaining studies did not report the standard deviations [18, 23, $24,36,38]$, and two studies reported the medians and interquartile ranges $[18,24]$; therefore, they could not be used in the meta-analysis. Ten of the studies defined the LOS as the "length of the hospital stay" and two studies $[3,26]$ defined the LOS as the "postoperative LOS". Only the "length of the hospital stay" was used in the meta-analysis. The mean LOS was significantly shorter in the LA group compared with that in the OA group (MD $-1.01,95 \%$ CI: $-1.61-0.41 ; P=0.001)$, but the analysis showed heterogeneity $\left(P<0.001 ; \mathrm{I}^{2}=86 \%\right)$.

Twelve of the studies reported the operative times $[3,16,17$, $20,21,23-25,30,31,36,38]$, and, of these, eight reported the means and standard deviations $[3,16,17,20,21,25,30,31]$. The four remaining studies did not report the standard deviations [23, 24, 36, 38], and one study [24] reported the median and the interquartile range; therefore, these studies could not be used in the meta-analysis.There were no significant differences between the LA and the OA groups with respect to the operative time (MD 2.23, 95\% CI: $-3.20-7.65 ; P=0.42$ ) or 


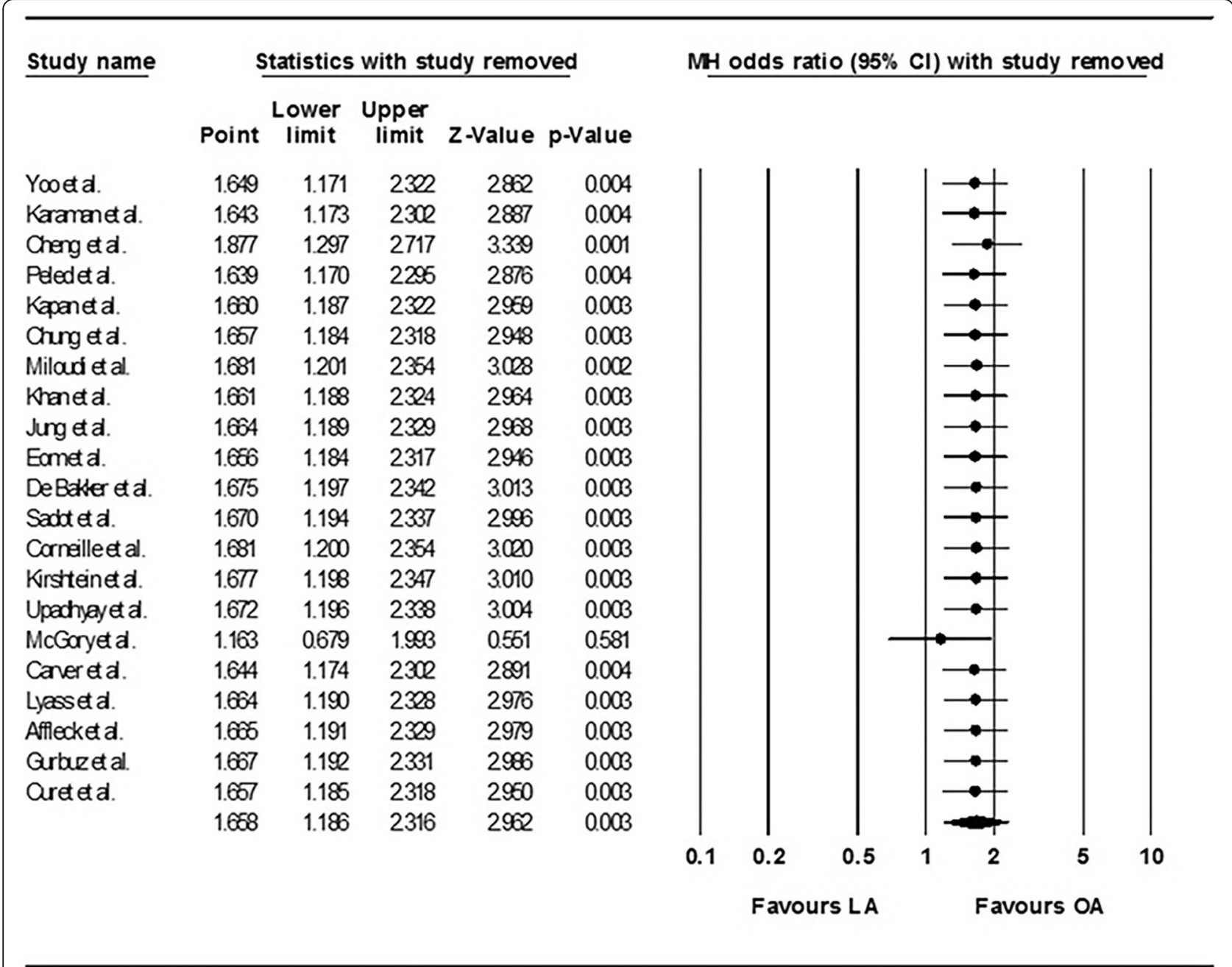

Fig. 3 Sensitivity analysis that examined the influence of individual studies on the pooled estimates of fetal loss. LA: laparoscopic appendectomy; OA: open appendectomy; Cl: confidence interval

the intra-abdominal abscess rate (OR 0.79, 95\% CI: 0.33$1.85 ; P=0.58)[3,16,17,20,21,23,25,30]$.

\section{Meta-regression analysis}

Meta-regression analyses were conducted to evaluate whether the year in which the study was published, the presence of complicated appendicitis, the gestational age at surgery, the trimester, or the presence of a negative appendectomy influenced the meta-analysis outcomes, for example, fetal loss and preterm delivery. None of the meta-regression analyses were statistically significant (Table 3 ). The meta-regression analyses showed trends towards a decreasing OR for fetal loss in association with a more recent publication year and an increasing OR for fetal loss in association with a higher complicated appendicitis rate (Fig. 6).

\section{Publication bias}

The funnel plots for fetal loss and preterm delivery are presented in Fig. 7. The contours are almost symmetrical, indicating that there was no evidence of publication bias.

\section{Discussion}

The findings from this systematic review and metaanalysis showed that it is not reasonable to conclude that LA during pregnancy might be associated with a greater risk of fetal loss. Indeed, no significant differences were observed between the LA and OA groups with respect to preterm delivery, the birth weight, the Apgar scores, the operative time, or intra-abdominal abscess formation after surgery. The results from this meta-analysis also showed that compared with OA, 


\begin{tabular}{|c|c|c|c|c|c|c|c|c|c|c|c|}
\hline Study or Subgroup & $\begin{array}{r}\text { LA } \\
\text { Events }\end{array}$ & Total & $\begin{array}{r}\text { OA } \\
\text { Events }\end{array}$ & Total & Weight & $\begin{array}{c}\text { Odds Ratio } \\
\text { M-H. Fixed. } 95 \% \mathrm{Cl}\end{array}$ & Year & & $\begin{array}{r}\text { Odds } \\
\text { M-H, Fixe }\end{array}$ & $\begin{array}{l}\text { Ratio } \\
\text { d. } 95 \% \mathrm{Cl}\end{array}$ & \\
\hline Yoo et al. & 2 & 24 & 4 & 56 & $4.0 \%$ & $1.18[0.20,6.93]$ & 2016 & & & & \\
\hline Karaman et al. & 3 & 12 & 9 & 36 & $6.1 \%$ & $1.00[0.22,4.52]$ & 2015 & & & & \\
\hline Cheng et al. & 7 & 128 & 74 & 653 & $41.7 \%$ & $0.45[0.20,1.01]$ & 2014 & & & & \\
\hline Peled et al. & 5 & 26 & 14 & 59 & $12.6 \%$ & $0.77[0.24,2.40]$ & 2013 & & & & \\
\hline Chung et al. & 2 & 22 & 4 & 39 & $4.8 \%$ & $0.88[0.15,5.21]$ & 2012 & & & & \\
\hline Khan et al. & 4 & 52 & 6 & 66 & $8.9 \%$ & $0.83[0.22,3.12]$ & 2011 & & & & \\
\hline Jung et al. & 0 & 4 & 2 & 21 & $1.5 \%$ & $0.87[0.04,21.36]$ & 2010 & & & & \\
\hline Eom et al. & 0 & 15 & 3 & 28 & $4.4 \%$ & $0.24[0.01,4.86]$ & 2009 & & & & \\
\hline De Bakker et al. & 1 & 12 & 1 & 3 & $2.7 \%$ & $0.18[0.01,4.26]$ & 2008 & & & & \\
\hline Sadot et al. & 12 & 41 & 3 & 16 & $5.5 \%$ & $1.79[0.43,7.45]$ & 2007 & & & & \\
\hline Corneille et al. & 1 & 9 & 5 & 40 & $3.0 \%$ & $0.88[0.09,8.56]$ & 2006 & & & & \\
\hline Upadhyay et al. & 1 & 4 & 0 & 2 & $0.8 \%$ & $2.14[0.06,77.54]$ & 2005 & & & & \\
\hline Carver et al. & 2 & 17 & 0 & 11 & $0.9 \%$ & $3.71[0.16,84.92]$ & 2004 & & & & \\
\hline Lyass et al. & 0 & 11 & 0 & 11 & & Not estimable & 2003 & & & & \\
\hline Affleck et al. & 3 & 19 & 2 & 18 & $3.1 \%$ & $1.50[0.22,10.22]$ & 2002 & & & & \\
\hline Gurbuz et al. & 0 & 5 & 0 & 4 & & Not estimable & 2001 & & & & \\
\hline Total $(95 \% \mathrm{Cl})$ & & 401 & & 1063 & $100.0 \%$ & $0.76[0.51,1.15]$ & & & & & \\
\hline Total events & 43 & & 127 & & & & & & & & \\
\hline $\begin{array}{l}\text { Heterogeneity: } \mathrm{Chi}^{2}= \\
\text { Test for overall effect: }\end{array}$ & $\begin{array}{l}.59, \mathrm{df}=1 \\
=1.30(\mathrm{P}\end{array}$ & $\begin{array}{l}13(P= \\
P=0.19\end{array}$ & $0.92) ;\left.\right|^{2}=$ & $=0 \%$ & & & & 0.005 & $\begin{array}{ll}0.1 & 1 \\
\text { Favours [LA] }\end{array}$ & $\begin{array}{c}10 \\
\text { Favours }[\mathrm{OA}]\end{array}$ & 200 \\
\hline
\end{tabular}

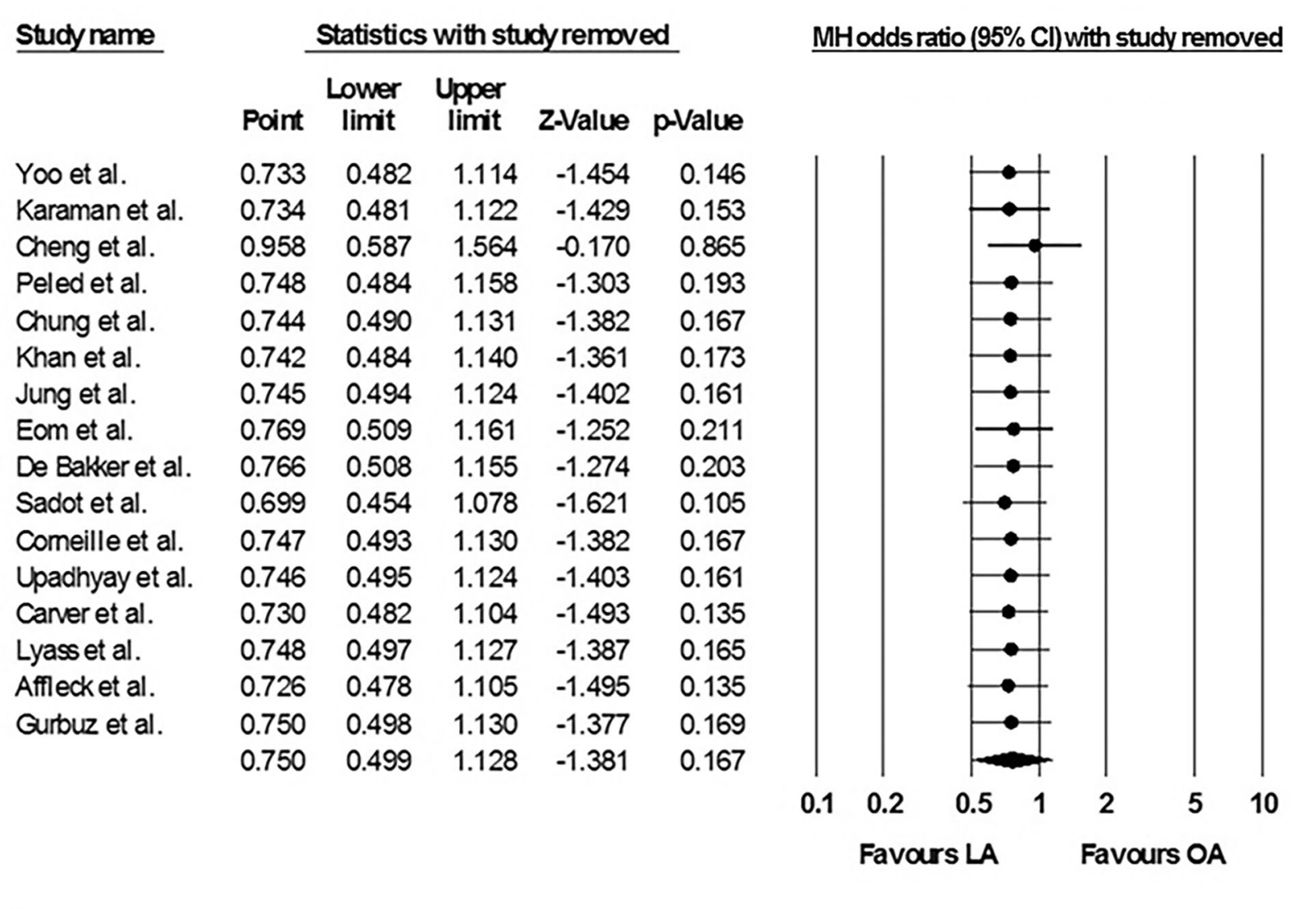

Fig. 5 Sensitivity analysis that examined the influence of individual studies on the pooled estimates of preterm delivery. LA: laparoscopic appendectomy; OA: open appendectomy; Cl: confidence interval 
Table 2 Summary of the meta-analyses of the pregnancy and surgical outcomes from laparoscopic appendectomy and open appendectomy

\begin{tabular}{lllllll}
\hline & Number of Studies & $\begin{array}{l}\text { Pooled number of } \\
\text { patients (LA/OA) }\end{array}$ & $\begin{array}{l}\text { Test for Heterogeneity } \\
\left(P \text { value, } I^{2}\right)\end{array}$ & Model & Pooled outcome & $P$ value* \\
\hline Birth Weight (gram) & 7 & $172 / 237$ & $1.00,0 \%$ & Fixed & MD: 0.01(-0.09-0.10) & 0.88 \\
Apgar (1 min) & 5 & $125 / 162$ & $0.03,66 \%$ & Random & MD: 0.12(-0.18-0.08) & 0.43 \\
Apgar (5 min) & 4 & $113 / 106$ & $<0.001,84 \%$ & Random & MD: $-0.02(-0.16-0.12)$ & 0.76 \\
Wound Infection (n) & 7 & $1096 / 706$ & $0.15,36 \%$ & Fixed & OR: $0.40(0.21-0.76)$ & 0.005 \\
Operative Time (min) & 8 & $1082 / 684$ & $<0.001,80 \%$ & Random & MD: $2.23(-3.20-7.65)$ & 0.42 \\
Hospital Stay (days) & 10 & $1106 / 756$ & $<0.001,86 \%$ & Random & MD: $-1.01(-1.61--0.41)$ & 0.001 \\
Intra-abdominal & 7 & $1090 / 702$ & $0.55,0 \%$ & Fixed & OR: $0.79(0.33-1.85)$ & 0.58
\end{tabular}

*P value for pooled result

$O R$ odds ratio, $M D$ mean difference

LA might be associated with a lower risk of wound infection and a shorter LOS.

According to the current SAGES guidelines, LA may be performed safely in pregnant patients who have a suspicion of appendicitis [28]. The present authors also prefer LA over OA for pregnant patients with presumed appendicitis because of its effectiveness in access to the appendix, visualization, and reduce surgical complications. Although our data are not yet enough to evaluate pregnancy outcomes in pregnant women who underwent LA, there was no complication such as fetal loss after LA. Furthermore, the publications from recent studies have reported that LA can be performed safely during any pregnancy trimester $[16,17,20,33]$. However, both a systematic review [5] and a meta-analysis [4] concluded that there was low grade evidence to suggest that LA in pregnant women might be associated with a greater risk of fetal loss. Thus, the safety of LA during pregnancy remains controversial.

The findings from the current updated meta-analysis showed that fetal loss was significantly higher in pregnant women who underwent LA compared with those who underwent OA. However, the sensitivity analysis revealed that this finding was greatly influenced by the study undertaken by McGory et al. [34] that had the largest sample size among the pooled studies. Although there was no publication bias and heterogeneity was not evident in this analysis, meta-regression analyses were performed to determine whether fetal loss was associated with the publication year, complicated appendicitis, the gestational age, the trimester, or negative appendectomy. None of the meta-regression analyses were statistically significant. However, the meta-regression analyses showed trends towards a decreasing OR for fetal loss in association with a more recent publication year and an increasing OR for fetal loss in association with a higher complicated appendicitis rate. These results are supported by those from more recent studies $[3,16-19,25]$ that showed that, with the exception of two studies [34, 35], LA appeared to be a safe, feasible, and efficacious approach during pregnancy. Moreover, a previous study's findings demonstrated that fetal outcomes are more likely to be adversely affected by the type of infection and misdiagnosed disease rather than

Table 3 Meta-regression analyses of the effects of each covariate on fetal loss and preterm delivery

\begin{tabular}{|c|c|c|c|c|c|c|c|c|}
\hline \multirow[b]{2}{*}{ Covariates } & \multicolumn{4}{|l|}{ Fetal loss } & \multicolumn{4}{|l|}{ Preterm delivery } \\
\hline & Number of studies & Point estimate & $95 \% \mathrm{Cl}$ & $P$ value & Number of studies & Point estimate & $95 \% \mathrm{Cl}$ & $P$ value \\
\hline Publication year & 21 & -0.045 & $(-0.130-0.040)$ & 0.304 & 16 & -0.055 & $(-0.153-0.043)$ & 0.271 \\
\hline Mean age & 16 & -0.008 & $(-0.322-0.305)$ & 0.957 & 13 & 0.013 & $(-0.188-0.214)$ & 0.902 \\
\hline Mean GA & 15 & 0.007 & $(-0.140-0.153)$ & 0.93 & 13 & -0.028 & $(-0.142-0.086)$ & 0.633 \\
\hline Proportion of 1st & 9 & -0.02 & $(-0.102-0.062)$ & 0.635 & 8 & 0.001 & $(-0.050-0.052)$ & 0.97 \\
\hline Proportion of 2nd & 9 & 0.003 & $(-0.080-0.060)$ & 0.952 & 8 & 0.004 & $(-0.040-0.048)$ & 0.849 \\
\hline Proportion of 3rd & 9 & 0.012 & $(-0.054-0.347)$ & 0.729 & 8 & -0.005 & $(-0.042-0.033)$ & 0.8 \\
\hline Proportion of CA & 10 & 0.055 & $(-0.015-0.124)$ & 0.123 & 7 & -0.002 & $(-0.095-0.091)$ & 0.969 \\
\hline Proportion of NA & 13 & 0.009 & $(-0.057-0.281)$ & 0.778 & 9 & 0.032 & $(-0.062-0.126)$ & 0.499 \\
\hline
\end{tabular}

Cl confidence interval; GA gestational age, CA complicated appendicitis, NA negative appendicitis 


\section{A Regression of the publication year on $\mathrm{MH}$ log odds ratio}

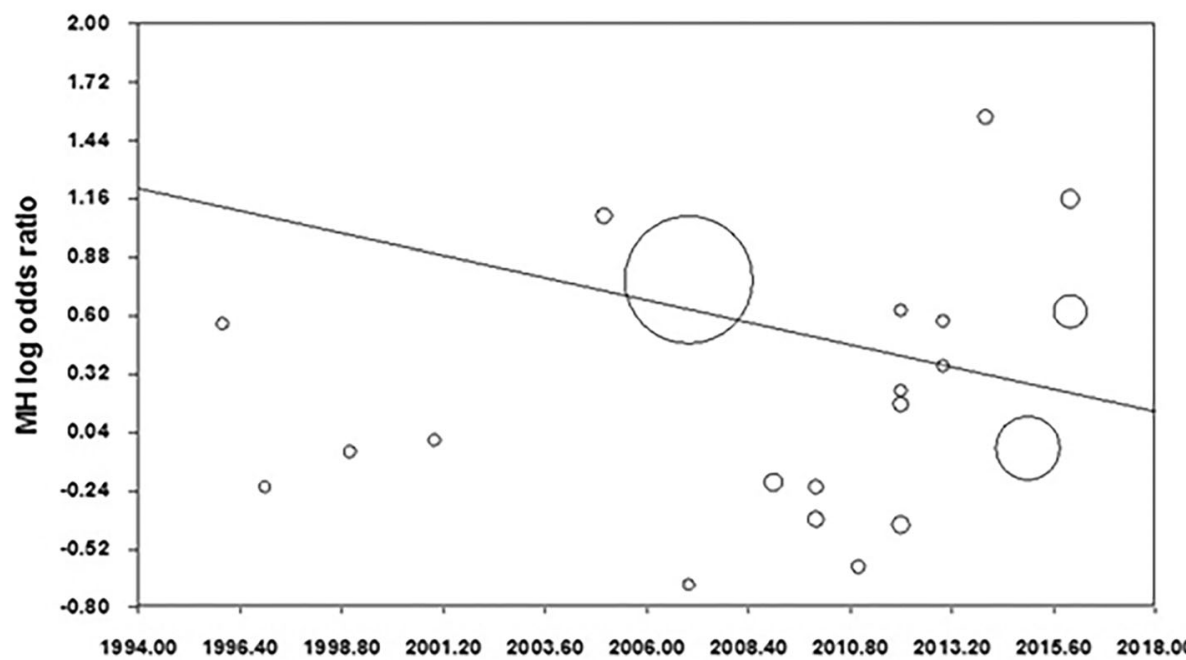

Publication year

\section{B Regression of complicated appendicitis on $\mathrm{MH}$ log odds ratio}

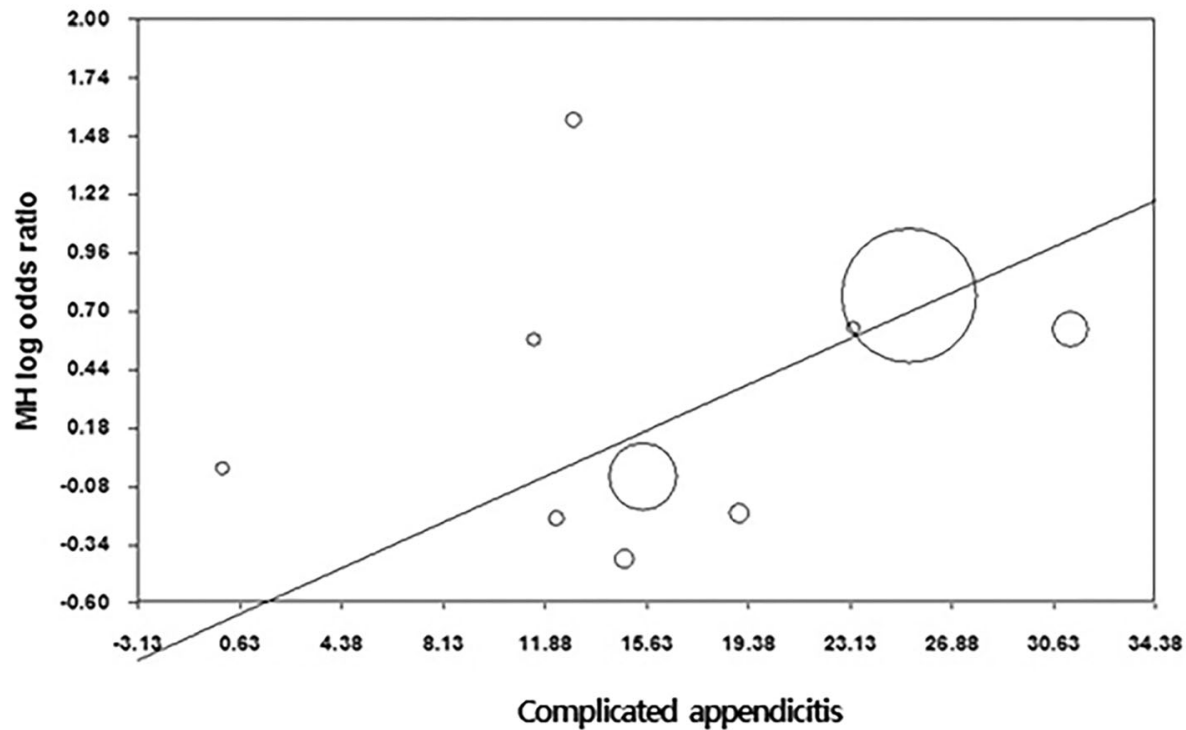

Fig. 6 Scatter plots of the meta-regression analyses of the effects of the publication year (a) and complicated appendicitis (b) on the odds ratios for fetal loss

by the laparoscopic approach itself [24]. Therefore, it is not reasonable to conclude that LA during pregnancy might be associated with a greater risk of fetal loss.

The effect of pneumoperitoneum is a major consideration in relation to laparoscopic surgery during pregnancy. Increasing the intra-abdominal pressure to induce pneumoperitoneum can reduce the venous return and cardiac output [40], resulting in maternal hypotension and hypoxia [41]. In addition, fetal acidosis may occur as a consequence of carbon dioxide pneumoperitoneum [42]. However, the findings from a previous study undertaken on an animal pregnancy model showed that the fetus was not adversely affected when the pneumoperitoneal pressure was elevated to $10-12 \mathrm{mmHg}$ for less than $30 \mathrm{~min}$ [43]. Furthermore, the SAGES guidelines recommend insufflation pressures of $10-15 \mathrm{mmHg}$ for pregnant patients [28]. Therefore, there was insufficient evidence to determine whether the risk of fetal loss was greater in association with LA or OA.

Although the precise cause of preterm delivery after surgery during pregnancy remains unclear, the findings from previous studies have indicated that preterm 

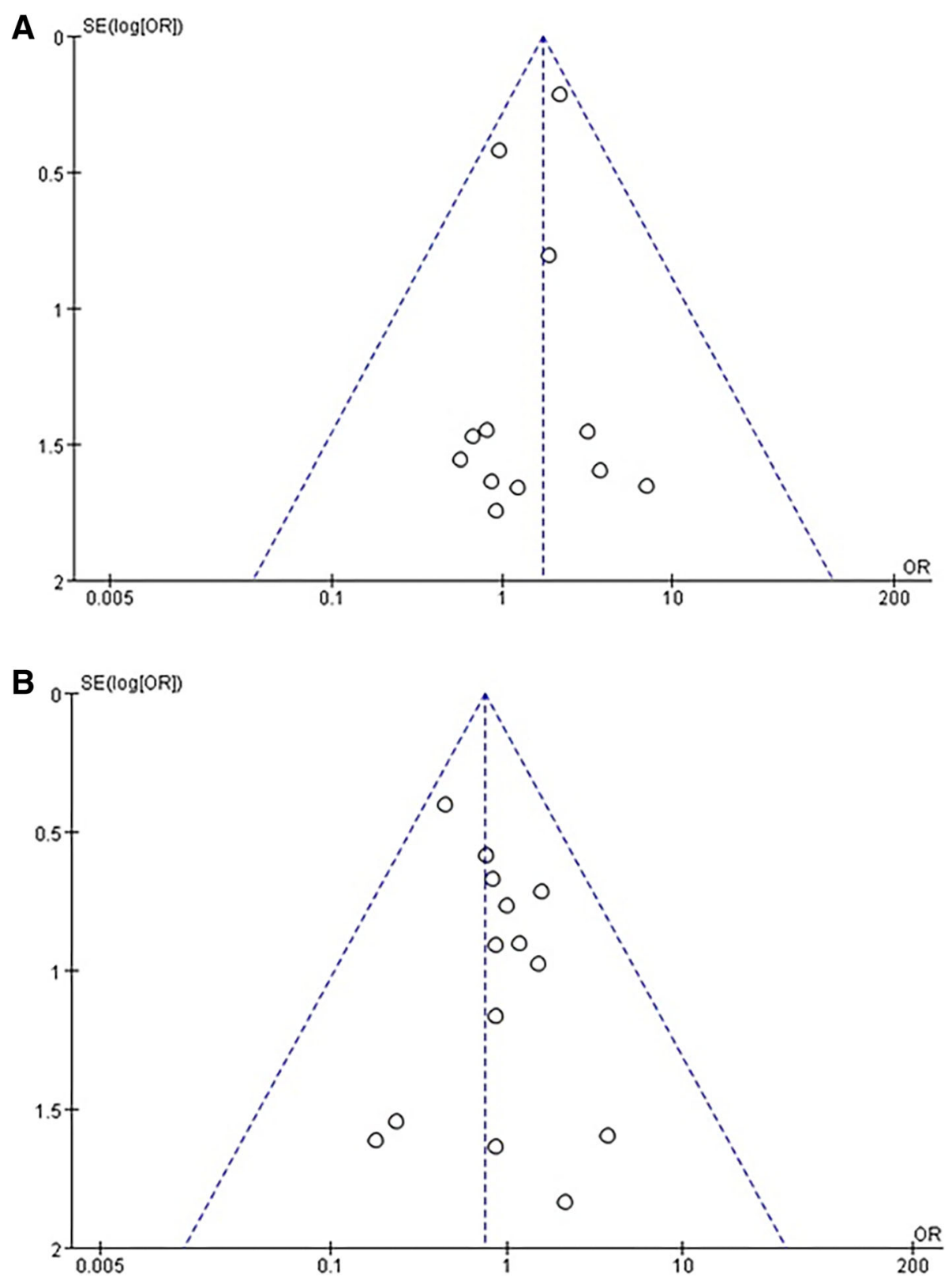

Fig. 7 Funnel plots of the studies that described fetal loss (a) and preterm delivery (b)

delivery was associated with uterine irritability during the operations $[44,45]$. While the results from this updated meta-analysis showed that there was no significant difference between LA and OA with respect to preterm delivery, a trend towards an increasing risk of preterm delivery was evident in those who underwent OA compared with those who underwent LA, which differed from the findings from a previous meta-analysis [4]. Furthermore, the meta-regression analysis showed a trend towards a decreasing OR for preterm delivery in association with a more recent publication year, but the meta-analyses did not determine any significant differences between LA and OA with respect to the other pregnancy outcomes, for example, the birth weight and the Apgar scores, which concurs with the results from a previous meta-analysis [4].

Interestingly, the pooled results from this updated meta-analysis that were related to the primary outcomes, namely, fetal loss and preterm delivery, showed opposing trends in the two groups. These results could be attributed to a single study even though the two outcomes may be caused by different factors, for example, pneumoperitoneum and uterine irritability during the operation. If fetal loss and preterm delivery 
are caused by pneumoperitoneum and uterine irritability, respectively, during the operation, it is very interesting that the pooled results showed opposing trends in the two groups.

Postoperative complications are usually considered to evaluate the safety of surgical procedures. The results from this meta-analysis showed that the risk of wound infection was significantly lower in the LA group compared with that in the OA group. In contrast, the findings from a previous meta-analysis suggested that there was no significant difference between LA and OA during pregnancy with respect to wound infection [4]. However, the findings from a recently published meta-analysis showed that the rate of wound infection in the general population was significantly lower in the LA group compared with that in the OA group [46]. Moreover, the results from the current meta-analysis showed a tendency, albeit one that was not statistically significant, to favor LA because of the lower risk of intra-abdominal abscesses, which concurs with the results from the previous meta-analysis that used data from the general population [46].

The results from the present meta-analysis revealed that the mean LOS was significantly shorter in the LA group compared with that in the OA group, a finding that concurs with those reported from previous meta-analyses that used data from pregnant women and the general population $[4,46]$; hence, this can be considered a benefit of LA. The operative time was longer in the LA group compared with that in the OA group, but the difference between the groups was not statistically significant. This result concurs with that from a meta-analysis that used data from pregnant women [4]. Moreover, the findings from a recent study of the general population suggested that LA took significantly longer to complete than OA [46]. Thus, LA shows a trend towards longer operative times compared with OA in pregnant women.

We updated the meta-analysis that was conducted during a previous related study. This meta-analysis evaluated the effects of LA and OA on pregnancy and surgical outcomes. One of the study's strengths was related to the sensitivity and meta-regression analyses of the pregnancy outcomes that were performed to corroborate the findings from the meta-analysis. Another strength of this study was the rigorous literature search. Despite these strengths, there are some limitations to the present study. First, there were no randomized controlled trials among the studies analyzed. Second, the studies analyzed tended to involve small study populations. Third, the outcome assessments differed and different definitions for each variable existed among the studies.

\section{Conclusions}

In summary, the sensitivity analysis of the studies that comprised this meta-analysis showed that one study by
McGory et al. [34] had a disproportionately high influence on the findings from this meta-analysis, and that when this study [34] was removed from the analysis, no significant difference was evident between LA and OA in relation to the risk of fetal loss. Thus, the findings from this systematic review and updated meta-analysis show that it is not reasonable to accept without question the conclusions from a previous systematic review and meta-analysis that indicated that LA in pregnant women might be associated with a greater risk of fetal loss. Furthermore, there was no significant difference between the LA and OA groups with respect to preterm delivery. Compared with OA, LA was associated with lower wound infection rates and shorter LOS. Based on our results and recent literatures, we suggest that LA shows non-inferior safety with respect to pregnancy outcomes but superior with regard to surgical outcomes compared with OA in pregnant women with suspected appendicitis. Although it is difficult to conduct randomized trials on pregnant women, large scale and well-designed trials are needed to clarify the present findings. This systematic review and updated meta-analysis will help guide surgeons in their decision making in relation to treatment options for appendicitis during pregnancy.

\section{Abbreviations \\ Cl: Confidence interval; GA: Gestational age; LA: Laparoscopic appendectomy; LOS: Length of stay; MD: Mean difference; OA: Open appendectomy; OR: Odds ratio}

\section{Acknowledgments}

The authors thank HY Kim for helping with the statistical analyses, and they also thank all of the coordinators for their valuable help and cooperation.

\section{Funding}

Not applicable.

\section{Availability of data and materials}

All data generated or analyzed during this study are included in this published article.

\section{Authors' contributions}

SHL and JGL designed this study. SHL, JYL and YYC collected literatures and conducted the analysis of pooled data. YYC helped to draft the manuscript. SHL wrote the manuscript. All authors contributed to review the manuscript. All authors read and approved the final manuscript.

Ethics approval and consent to participate

Not applicable.

Consent for publication

Not applicable.

Competing interests

The authors declare that they have no competing interests.

\section{Publisher's Note}

Springer Nature remains neutral with regard to jurisdictional claims in published maps and institutional affiliations.

Author details

'Department of Surgery, Yonsei University College of Medicine, 50-1

Yonsei-ro, Seodaemun-gu, Seoul 03722, Republic of Korea. ${ }^{2}$ Department of 
Trauma Surgery, Trauma Center, Chungbuk National University Hospital, Cheongju, Republic of Korea.

\section{Received: 12 April 2018 Accepted: 9 April 2019 Published online: 25 April 2019}

\section{References}

1. Zingone F, Sultan AA, Humes DJ, West J. Risk of acute appendicitis in and around pregnancy: a population-based cohort study from England. Ann Surg. 2015;261:332-7.

2. Guttman R, Goldman RD, Koren G. Appendicitis during pregnancy. Can Fam Physician. 2004;50:355-7.

3. Kirshtein B, Perry ZH, Avinoach E, Mizrahi S, Lantsberg L. Safety of laparoscopic appendectomy during pregnancy. World J Surg. 2009;33:475-80.

4. Wilasrusmee C, Sukrat B, McEvoy M, Attia J, Thakkinstian A. Systematic review and meta-analysis of safety of laparoscopic versus open appendicectomy for suspected appendicitis in pregnancy. Br J Surg. 2012; 99:1470-8

5. Walker HG, Al Samaraee A, Mills SJ, Kalbassi MR. Laparoscopic appendicectomy in pregnancy: a systematic review of the published evidence. Int J Surg. 2014;12:1235-41.

6. Weingold AB. Appendicitis in pregnancy. Clin Obstet Gynecol. 1983:26:801-9.

7. Gilo NB, Amini D, Landy HJ. Appendicitis and cholecystitis in pregnancy. Clin Obstet Gynecol. 2009:52:586-96.

8. Yilmaz HG, Akgun Y, Bac B, Celik Y. Acute appendicitis in pregnancy--risk factors associated with principal outcomes: a case control study. Int J Surg. 2007:5:192-7.

9. Ueberrueck T, Koch A, Meyer L, Hinkel M, Gastinger I. Ninety-four appendectomies for suspected acute appendicitis during pregnancy. World J Surg. 2004:28:508-11.

10. Rollins MD, Chan KJ, Price RR. Laparoscopy for appendicitis and cholelithiasis during pregnancy: a new standard of care. Surg Endosc. 2004; 18:237-41

11. Al-Qudah MS, Amr M, Sroujieh A, Issa A. Appendectomy in pregnancy: the experience of a university hospital. J Obstet Gynaecol. 1999:19:362-4.

12. Palanivelu C, Rangarajan M, Senthilkumaran S, Parthasarathi R. Safety and efficacy of laparoscopic surgery in pregnancy: experience of a single institution. J Laparoendosc Adv Surg Tech A. 2007;17:186-90.

13. Park SH, Park MI, Choi JS, Lee JH, Kim HO, Kim H. Laparoscopic appendectomy performed during pregnancy by gynecological laparoscopists. Eur J Obstet Gynecol Reprod Biol. 2010;148:44-8.

14. Andersen B, Nielsen TF. Appendicitis in pregnancy: diagnosis, management and complications. Acta Obstet Gynecol Scand. 1999;78:758-62.

15. Fallon WF Jr, Newman JS, Fallon GL, Malangoni MA. The surgical management of intra-abdominal inflammatory conditions during pregnancy. Surg Clin North Am. 1995;75:15-31.

16. Yoo KC, Park JH, Pak KH, Kim KY, Lee BH, Kim BC, et al. Could laparoscopic appendectomy in pregnant women affect obstetric outcomes? A multicenter study. Int J Color Dis. 2016;31:1475-81.

17. Karaman E, Aras A, Çim N, Kolusarı A, Kızıltan R, Celik S, et al. Maternal and fetal outcomes after laparoscopic vs. open appendectomy in pregnant women: data from two tertiary referral centers. Ginekol Pol. 2016;87:98-103.

18. Cheng HT, Wang YC, Lo HC, Su LT, Soh KS, Tzeng CW, et al. Laparoscopic appendectomy versus open appendectomy in pregnancy: a populationbased analysis of maternal outcome. Surg Endosc. 2015;29:1394-9.

19. Peled $Y$, Hiersch L, Khalpari O, Wiznitzer A, Yogev Y, Pardo J. Appendectomy during pregnancy--is pregnancy outcome depending by operation technique? J Matern Fetal Neonatal Med. 2014;27:365-7.

20. Chung JC, Cho GS, Shin EJ, Kim HC, Song OP. Clinical outcomes compared between laparoscopic and open appendectomy in pregnant women. Can J Surg. 2013;56:341-6.

21. Khan AM, Dalwani AG, Memon M, Shaikh U. Appendecectomy during pregnancy. A comparison of laparoscopic with open appendicectomy in respect of safety and morbidity to mother and fetus. Medical Forum Monthly. 2012;23:51-5

22. Jung SJ, Lee DK, Kim JH, Kong PS, Kim KH, Bae SW. Appendicitis during pregnancy: the clinical experience of a secondary hospital. J Korean Soc Coloproctol. 2012;28:152-9.

23. Eom JM, Hong JH, Jeon SW, Choi JS, Lee JH, Kim HO, et al. Safety and clinical efficacy of laparoscopic appendectomy for pregnant women with acute appendicitis. Ann Acad Med Singap. 2012;41:82-6.
24. de Bakker JK, Dijksman LM, Donkervoort SC. Safety and outcome of general surgical open and laparoscopic procedures during pregnancy. Surg Endosc. 2011;25:1574-8

25. Sadot E, Telem DA, Arora M, Butala P, Nguyen SQ, Divino CM. Laparoscopy: a safe approach to appendicitis during pregnancy. Surg Endosc. 2010;24: 383-9.

26. Corneille MG, Gallup TM, Bening T, Wolf SE, Brougher C, Myers JG, et al. The use of laparoscopic surgery in pregnancy: evaluation of safety and efficacy. Am J Surg. 2010;200:363-7.

27. Semm K. Endoscopic appendectomy. Endoscopy. 1983;15:59-64.

28. Guidelines Committee of the Society of American Gastrointestinal and Endoscopic Surgeons, Yumi H. Guidelines for diagnosis, treatment, and use of laparoscopy for surgical problems during pregnancy: this statement was reviewed and approved by the Board of Governors of the Society of American Gastrointestinal and Endoscopic Surgeons (SAGES), September 2007. It was prepared by the SAGES Guidelines Committee. Surg Endosc. 2008;22: 849-61.

29. Moher D, Liberati A, Tetzlaff J, Altman DG. The PRISMA group (2009). Preferred reporting items for systematic reviews and meta-analyses: the PRISMA statement Open Med. 2009:3:e123-30.

30. Cox TC, Huntington CR, Blair LJ, Prasad T, Lincourt AE, Augenstein VA, et al. Laparoscopic appendectomy and cholecystectomy versus open: a study in 1999 pregnant patients. Surg Endosc. 2016;30:593-602.

31. Kapan S, Bozkurt MA, Turhan AN, Gönenç M, Alış H. Management of acute appendicitis in pregnancy. Ulus Travma Acil Cerrahi Derg. 2013;19:20-4.

32. Miloudi N, Brahem M, Ben Abid S, Mzoughi Z, Arfa N, Tahar KM. Acute appendicitis in pregnancy: specific features of diagnosis and treatment. J Visc Surg. 2012;149:e275-9.

33. Upadhyay A, Stanten S, Kazantsev G, Horoupian R, Stanten A. Laparoscopic management of a nonobstetric emergency in the third trimester of pregnancy. Surg Endosc. 2007;21:1344-8.

34. McGory ML, Zingmond DS, Tillou A, Hiatt JR, Ko CY, Cryer HM. Negative appendectomy in pregnant women is associated with a substantial risk of fetal loss. J Am Coll Surg. 2007;205:534-40.

35. Carver TW, Antevil J, Egan JC, Brown CV. Appendectomy during early pregnancy: what is the preferred surgical approach? Am Surg. 2005;71:809-12.

36. Lyass S, Pikarsky A, Eisenberg VH, Elchalal U, Schenker JG, Reissman P. Is laparoscopic appendectomy safe in pregnant women? Surg Endosc. 2001; 15:377-9.

37. Affleck DG, Handrahan DL, Egger MJ, Price RR. The laparoscopic management of appendicitis and cholelithiasis during pregnancy. Am J Surg. 1999;178:523-9.

38. Gurbuz AT, Peetz ME. The acute abdomen in the pregnant patient. Is there a role for laparoscopy? Surg Endosc. 1997:11:98-102.

39. Curet MJ, Allen D, Josloff RK, Pitcher DE, Curet LB, Miscall BG, et al. Laparoscopy during pregnancy. Arch Surg. 1996:131:546-50 discussion 550-1.

40. Westerband A, Van De Water J, Amzallag M, Lebowitz PW, Nwasokwa ON Chardavoyne $\mathrm{R}$, et al. Cardiovascular changes during laparoscopic cholecystectomy. Surg Gynecol Obstet. 1992;175:535-8.

41. Kammerer WS. Nonobstetric surgery during pregnancy. Med Clin North Am. 1979;63:1157-64.

42. Soper NJ, Hunter JG, Petrie RH. Laparoscopic cholecystectomy during pregnancy. Surg Endosc. 1992;6:115-7.

43. Curet MJ, Vogt DA, Schob O, Qualls C, Izquierdo LA, Zucker KA. Effects of CO2 pneumoperitoneum in pregnant ewes. J Surg Res. 1996;63:339-44.

44. Soriano D, Yefet Y, Seidman DS, Goldenberg M, Mashiach S, Oelsner G. Laparoscopy versus laparotomy in the management of adnexal masses during pregnancy. Fertil Steril. 1999;71:955-60

45. Curet MJ. Special problems in laparoscopic surgery. Previous abdominal surgery, obesity, and pregnancy. Surg Clin North Am. 2000;80:1093-110.

46. Wei B, Oi CL, Chen TF, Zheng ZH, Huang JL, Hu BG, et al. Laparoscopic versus open appendectomy for acute appendicitis: a metaanalysis. Surg Endosc. 2011:25:1199-208. 